\title{
Identification and Analysis of Comfort Predictors in the Use of a Hand Tool
}

\author{
Monica Sharma ${ }^{1}$, Awadhesh Kumar', Dipayan Das ${ }^{2}$ \\ ${ }^{1}$ Malaviya National Institute of Technology \\ J.L.N Marg, Jaipur, India \\ msharma.dms@mnit.ac.in; akbhardwaj.mech@mnit.ac.in \\ ${ }^{2}$ Malaviya National Institute of Technology \\ J.L.N Marg, Jaipur, India \\ dipayandas03@gmail.com
}

\begin{abstract}
Comfort is a well-balanced state of physiological, psychological and physical factors of a human being and its environment. This paper is aimed at identifying the factors that determine comfort in using hammer according to the users. Before the primary data collection underlying descriptors were identified from literature. Further investigation was done to validate the identified descriptors with respect to comfort in using hammer. Principal component analysis with varimax rotation was used to classify the descriptors into factors. Eight factors were classified (functionality, body posture and muscles, tool characteristics, etc.). Handle and hand interaction was found to be the most important factor of expected comfort followed by aesthetics. For overall comfort, functionality was found to be the most important factor followed by body posture and muscles. Moreover, fit of tool to the hand and some more comfort predicting descriptors were identified whereas overall comfort predicting descriptors identified were ease of use, no inflamed skin, functional, easy to carry, and low hand grip force supply.
\end{abstract}

Keywords: Comfort Predicting Descriptors; Principal Component Analysis; Expected Comfort Predicting Factors.

\section{Introduction}

Different hand tools are being used by people over a million years but the design of the hand tools remain almost the same as in the past [1]. The use of a hand tool by any person within an environment results in perceive body effects which may be influenced by expectations and this perceived effect could be comfort, discomfort or no feelings [2]. Perceived discomfort in using hand tool for longer term could cause musculoskeletal disorder [3]. Therefore, providing comfort in using hand tool is always been an important issue in the design and in evaluation of a hand tool [4]. Especially comfort could play an important role in product buying decisions [5].

Moreover comfort has an impact on worker's productivity [6]. So before going to start the design of a comfortable hand tool it is important to know the factors that improve comfort in using it as a hand tool can never be comfortable in itself, unless it becomes comfortable in its use.

Different object measurements were performed to evaluate hand tools e.g., muscle activity [7-9], distribution of grip force [8]; [10] and hand-wrist postures induced [9]; [11] but still their relationships with user's comfort experience are unknown. The current study aims to identify the descriptors that predict comfort in using hammer and if possible classify the descriptors into meaningful groups or factors and identify the comfort predicting factors. These goals were achieved by subjective measurement technique using a comfort questionnaire by collecting the descriptors related to comfort/discomfort in using hand tools.

\section{Methodology}

Selection was made in the pre-study. In main study the comfort predicting descriptors were identified and they were classified into factors to identify the comfort predicting factors. 


\subsection{Pre-study}

The objective of the pre-study was to (1) prepare a list of comfort/discomfort relating descriptors collected from literature (2) check if there is any difference between the descriptors underlying comfort and discomfort. These objectives were achieved in three steps.

First, a search for the papers containing "comfort", "discomfort", "hand tools", "user experience and hand tool", "ergonomics and tools" was made and a number of papers were found. A list of descriptors was composed collecting the descriptors from these papers.

Second, 20 experienced users (Group A) from different carpentry shops in Jaipur were asked to rate the predictors in the questionnaire with respect to comfort while using the hammer. Another 20 group of people (inexperienced users- Group B) who visited the shops randomly were asked to rate the predictors in the same questionnaire with respect to expected comfort in case they use a hammer.

Third, the participants were asked to rate the list of descriptors on a 3 point scale $(1=$ related to (dis)comfort, $2=$ not related to (dis)comfort, $3=$ do not know) [12]. Descriptor rated by more than $70 \%$ of the respondents related to comfort/discomfort was considered as meaningful descriptor [13] and selected for the main study.

\subsection{Main study}

From the results of pre-study it was found that the distribution of the mean of the descriptors is same across the groups. So the descriptors were treated as same for underlying comfort/discomfort (see Section 3). The objective of the main study was to (1) find out which descriptors are the predictors of comfort in using hammer among the descriptors which are selected in the pre-study (2) classify the descriptors into factors (groups of descriptors) and find out which of the factors are the predictors of comfort in using hammer.

In this study the same 40 respondents who participated in pre-study were chosen; mean age 43.0 years with a range from 27 to 58 years. The current study was conducted in two parts to answer the research questions.

\section{Apparatus}

\subsection{Comfort questionnaire}

Based on the results of pre-study a comfort questionnaire was prepared comprising of 40 descriptors which were rated by the majority of the respondents. A 7 point likert scale $(1=$ totally disagree to $7=$ totally agree) was used to rate the questionnaire. The questionnaire also consists of the questions asking for expected comfort at first sight and overall comfort after use and rate on a 7 point scale ( $1=$ very uncomfortable to $7=$ very comfortable).

\subsection{Experimental setting \& task protocol}

A normally used claw hammer (Figure 1) weighing $823 \mathrm{~g}$ and having handle length of $52 \mathrm{~cm}$ was evaluated for this study. At first the subjects were asked for rating expected comfort experience by holding and looking at the hammer.

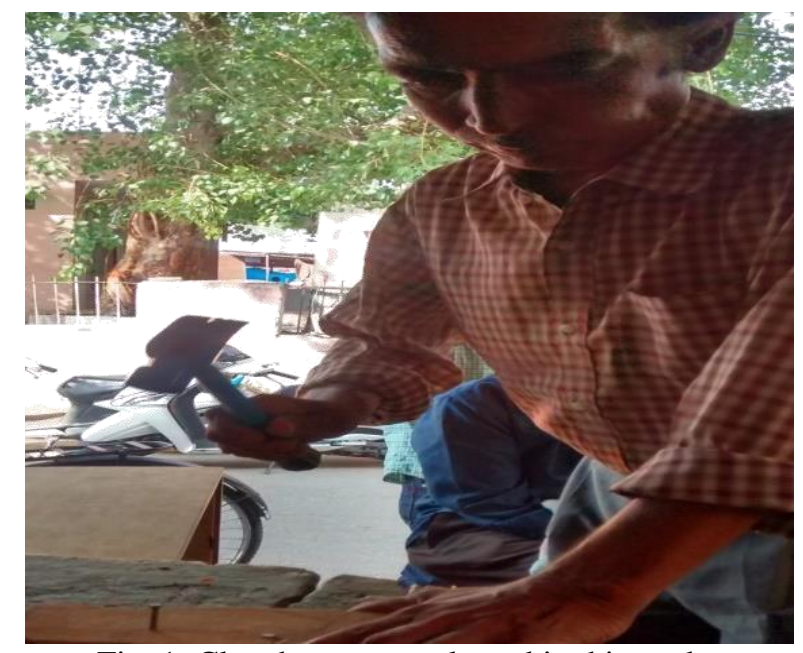

Fig. 1: Claw hammer evaluated in this study. 


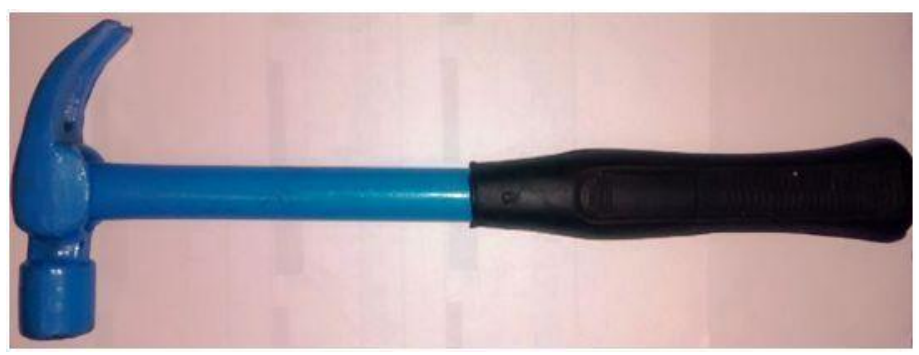

Fig. 2: The subject performing the task.

Then they were asked for pounding on 2 nails $(3 \mathrm{~cm}$ long) to get it into a wooden beam of $4 \mathrm{~cm}$ height, $50 \mathrm{~cm}$ long and $12 \mathrm{~cm}$ width as soon as possible without any rest break until the head of the nail touched the beam. A rest break of for 5 minutes was provided after completing every hammering-task and this procedure was repeated for all subjects. After completing the task the subjects were asked for rating the descriptors and overall comfort experience. Figure 2 shows the subject performing the task

\section{Data analysis}

Mann-Whitney U test was performed in the pre-study to check if there is any difference between comfort underlying descriptors and discomfort underlying descriptors. The result of Mann-Whitney $U$ test was analysed in the main study. Then multiple regression (forward selection procedure) was performed to identify the predictors of expected and overall comfort. Additionally PCA with varimax rotation was performed to classify the descriptors into factors. Then the factor scores of the factors were correlated with expected and overall comfort and comfort predicting factors were identified using then multiple regression (forward selection procedure).

\section{Results}

\subsection{Pre-study}

A number of papers were found from which 46 descriptors were collected [1]; [6-8]; [10]; [12], [14-16]. The result of Mann-Whitney $U$ test showed that the respondents did not rate the comfort questionnaire and discomfort questionnaire differently. So, it can be assumed that the same descriptors underlie comfort and discomfort.

Among the 46 descriptors collected from the literature 40 were selected based on $70 \%$ criterion. Some descriptors of general feelings (e.g., pleasurable, satisfied, happy), descriptors of appearance (e.g., nice appearance, nice color) and others (e.g., all weather proof) were removed from the list.

\subsection{Main study}

For identifying the expected comfort at first sight multiple regression was performed and the result predicted 2 descriptors (e.g., nice feeling handle, fits the hand). Figure 3 shows there standardize coefficient (beta) values.

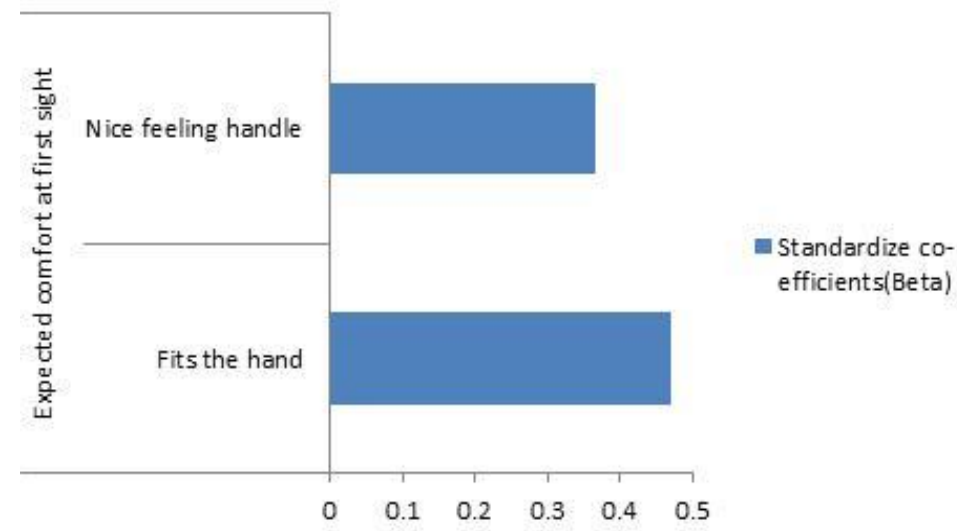

Fig. 3: Standardize coefficient values of expected comfort predicting descriptors. 
The multiple regression for overall comfort predicting descriptors identified 6 descriptors (e.g., no inflamed skin, easy to take along, functional, low hand grip force supply, relaxed working posture, easy in use) and the values of their standardize coefficient (beta) are shown in Figure 4.

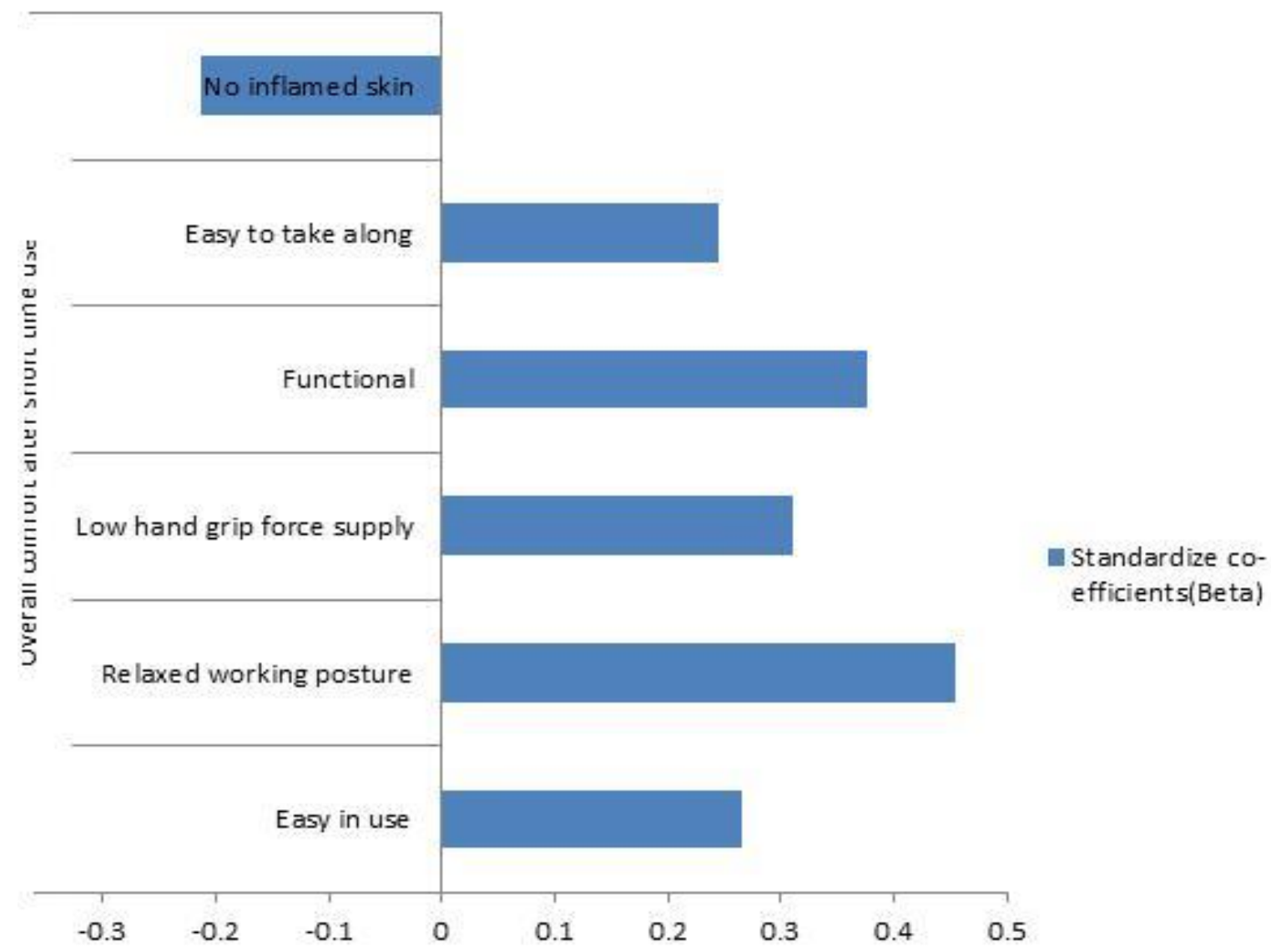

Fig. 4: Standardize coefficient values of overall comfort predicting descriptors.

The PCA with varimax rotation revealed 8 major factors with eigenvalue greater than 1, explaining $80.703 \%$ of the variance. Table 1 shows only the factor loadings of the 8 factors which are greater than 0.4 [12]. However, a sharp decrease in the eigenvalues after the sixth factor suggests predominance of the first six factors in the data. The first factor (Factor 1) contains descriptors as functional, reliable, good force transmission, high task performance, easy in use, easy to take along, safe and high product quality, this factor was labelled as "functionality". Relaxed working posture, no cramped muscles, low hand grip force supply, no sore muscles, no body part ache, handle hardness and no pain lie under Factor 2 which was named as "body posture and muscles".

Factor 3 contains weight of the tool, good friction between handle and hand, good handle roughness, handle shape, no slippery handle and handle size, this factor is named as "tool characteristics". Factor 4 was named as "adverse effect on hand" and it contains no irritation, no numbness, no blister, no inflamed skin, no pressure on hand, easy to take along and lack of tactile feelings. Factor 5 underlying descriptors are good force transmission, relaxed working posture, low hand grip force supply, no body part ache, fits the hand and nice feeling handle and according to the underlying descriptors this factor was named as "handle and hand interaction". Factor 6 was named as "quality" and as the name suggests the underlying descriptors are no force exerted from the tool, functional, reliable, high quality tool, no distraction of the worker from the task. Factor 7 was named as "feelings on palm" and no sweaty hand, handle does not feel clammy, no peak pressure underlie it. Functional colour looks professional, styling, luxury tool and solid design underlie the last factor (Factor 8) and it was labelled as "aesthetics". Then the correlations of these factors with expected comfort at first sight and overall comfort after short time use were obtained. Table 2 shows the correlation coefficient values for expected and overall comfort respectively. 
Table 1: Factor loadings of the descriptors (with varimax rotation) only the factor loading $>0.4$.

\begin{tabular}{|c|c|c|c|c|c|c|c|c|}
\hline & Factor 1 & Factor 2 & Factor 3 & Factor 4 & Factor 5 & Factor 6 & Factor 7 & Factor 8 \\
\hline Functional & 0.947 & & & & & 0.483 & & \\
\hline Reliable & 0.913 & & & & & 0.401 & & \\
\hline Good force transmission & 0.847 & & & & 0.487 & & & \\
\hline High task performance & 0.833 & & & & & & & \\
\hline Easy in use & 0.715 & & & & & & & \\
\hline Easy to take along & 0.606 & & & 0.468 & & & & \\
\hline Safe & 0.594 & & & & & 0.426 & & \\
\hline High product quality & 0.555 & & & & & & & \\
\hline Relaxed working posture & & 0.919 & & & & & & \\
\hline No cramped muscles & 0.87 & & & & & & & \\
\hline Low hand grip force supply & & & & & & & & \\
\hline & & 0.851 & & & 0.562 & & & \\
\hline No sore muscles & & 0.822 & & & & & & \\
\hline No body part ache & & 0.711 & & & 0.411 & & & \\
\hline Handle hardness & & 0.623 & & & & & & \\
\hline No pain & & 0.557 & & & & & & \\
\hline Weight of the tool & & 0.4 & 0.485 & & & & & \\
\hline Good friction between handle and hand & & & 0.846 & & & & 0.548 & \\
\hline Good handle roughness & & & 0.799 & & & & & \\
\hline Handle shape & & & 0.683 & & & & & \\
\hline No slippery handle & & & 0.634 & & & & & \\
\hline Handle size & & & 0.471 & & & & & \\
\hline No irritation & & & 0.44 & 0.468 & & & & \\
\hline No numbness & & & & 0.827 & & & & \\
\hline No blister & & & & 0.749 & & & & \\
\hline No inflamed skin & & & & 0.674 & & & & \\
\hline No pressure on hand & & & 0.402 & 0.485 & & & & \\
\hline Fits the hand & & & & & 0.897 & & & \\
\hline Nice feeling handle & & & & & 0.759 & & & \\
\hline Lack of tactile feelings & & & & 0.583 & & 0.412 & & \\
\hline No sweaty hands & & & & 0.409 & & & 0.477 & \\
\hline No force exerted from tool & & & & & & 0.611 & & \\
\hline High quality tool & 0.418 & & & & & 0.887 & & \\
\hline No distraction from work & & & & & & \begin{tabular}{|l|l|}
0.54 \\
\end{tabular} & & \\
\hline \multicolumn{3}{|l|}{ Handle does not feel clammy } & & & & & 0.798 & \\
\hline No peak pressure & & & & & & & 0.776 & \\
\hline Functional colour & & & & & & & & 0.792 \\
\hline Looks professional & & & & & & & & 0.765 \\
\hline Styling & & & & & & & & 0.724 \\
\hline Luxury tool & & & & & & & & 0.681 \\
\hline Solid design & & & & & & & & 0.643 \\
\hline
\end{tabular}


Table 2: Correlation coefficients of the factors.

\begin{tabular}{||l|l|l|}
\hline & Expected & \\
\hline & comfort & Overall comfort \\
\hline Functionality & $0.318^{*}$ & $0.655^{* *}$ \\
\hline Body posture \& muscles & 0.102 & $0.316^{*}$ \\
\hline Tool characteristics & 0.066 & 0.146 \\
\hline adverse effect on hand & 0.077 & $0.254^{*}$ \\
\hline Handle and hand interaction & $0.327^{*}$ & 0.305 \\
\hline Quality & -0.034 & -0.026 \\
\hline Feelings on palm & 0.036 & 0.065 \\
\hline Aesthetics & 0.185 & 0.124 \\
\hline
\end{tabular}

* the correlation is significant at the 0.05 level

$* *$ the correlation is significant at the 0.01 level.

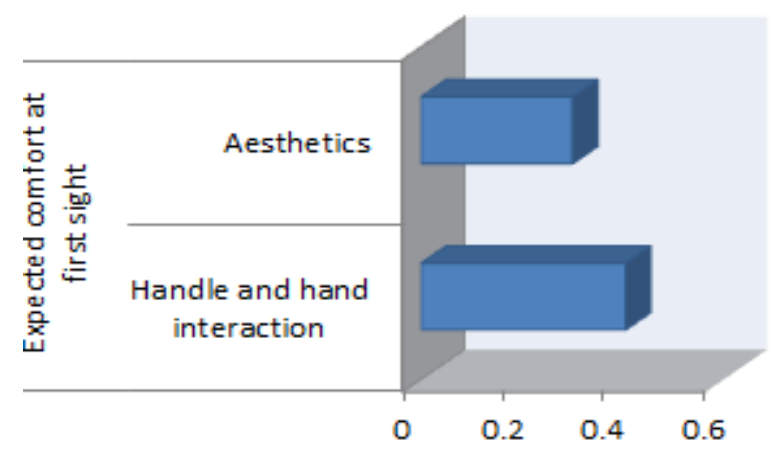

Standardize co-

efficients(Beta)

Fig. 5: Standardize coefficient values of expected comfort predicting factors.

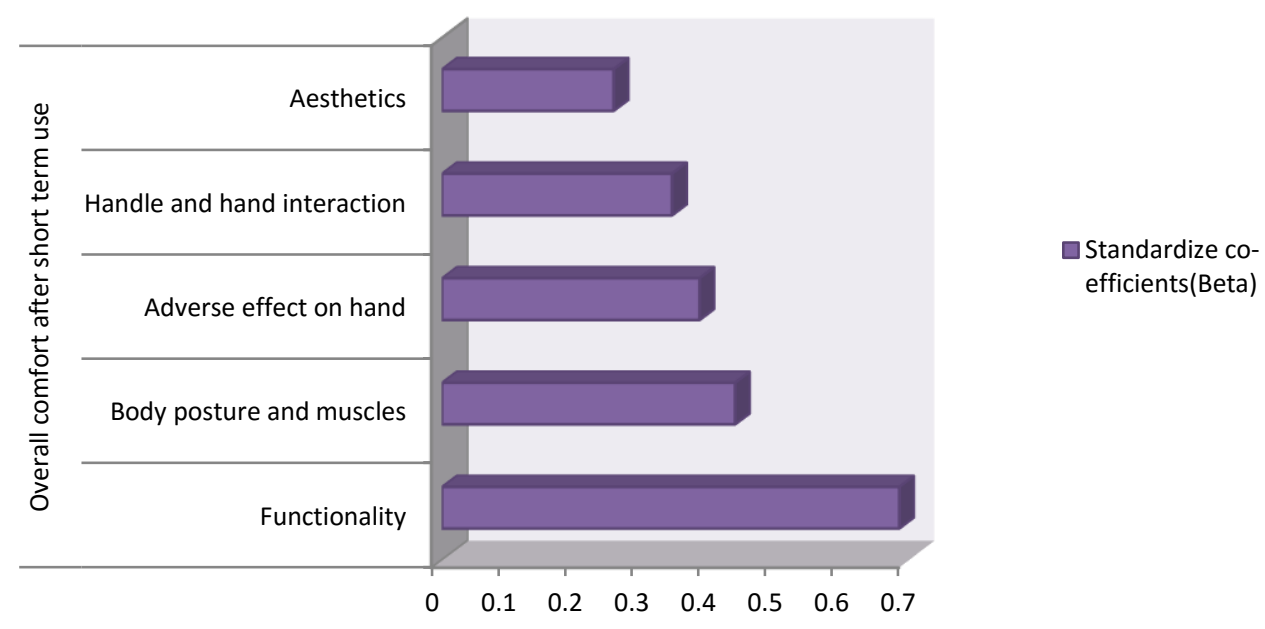

Fig. 6: Standardize coefficient values of expected comfort predicting factors.

\section{Discussion}

From the result of multiple regression for identifying expected comfort predicting descriptors it can be seen that 'fits the hand' $(\beta=0.471, p<0.01)$ more strongly influences expected comfort than 'nice feeling handle' $(\beta=0.367, p<0.05)$. But both are important for expected comfort as 'fits the hand' and 'nice feeling handle' are the first choice of a customer in product buying decisions. For overall comfort all the descriptors have expected signs, except 'no inflamed skin'. Probably 
this happened due to high co-linearity between descriptors. Among the six overall comfort predicting descriptors 'relaxed working posture' $(\beta=0.455, p<0.01)$ has the greatest influence on overall comfort followed by 'functional' $(\beta=0.377, p<0.01)$, 'low hand grip force supply' $(\beta=0.311, p<0.01)$, 'easy in use' $(\beta=0.267, p<0.05)$, 'easy to take along' $(\beta=0.245, p<0.05)$, 'no inflamed skin' $(\beta=-0.213, \mathrm{p}<0.05)$. PCA with varimax rotation classified eight factors out of which two factors i.e., "handle and hand interaction" $(\beta=0.406, p<0.01)$, "aesthetics" $(\beta=0.301, p<0.05)$ are identified as expected comfort predicting factors. Expected comfort has a great impact on product buying decisions. So in order to provide better expected comfort by holding and looking at the tool handle and hand interaction and aesthetics of the hammer are to be improved. As overall comfort after short time use of hammer five factors are identified as predictors. "Functionality" $(\beta=0.685, p<0.01)$ is the most important predictor followed by "body posture and muscles" $(\beta=0.437, p<0.05)$, "adverse effect on hand" $(\beta=0.384$, $\mathrm{p}<0.01)$, "handle and hand interaction" $(\beta=0.343, \mathrm{p}<0.01)$ and "aesthetics" $(\beta=0.256, \mathrm{p}<0.05)$.

It can be seen that "aesthetics" and "handle and hand interaction" are the common predictors of expected comfort at first sight and overall comfort after short time use. It can be interpreted from the results that a hammer with proper functionality can provide good comfort only when it fits the hand of the user and make the user free from adverse body effects. The result of this study is a little bit different from the other studies related to comfort where other hand tools such as screwdriver, plier, handsaw were evaluated [6-7]; [12]; [17] as the number of factors divided by PCA with varimax rotation is more. The result is also different from the study of Kuijt-Evers et al., 2007 as there aesthetics was found to be more important factor over functionality \& physical interaction in using screwdrivers. This implies that the relative importance of the descriptors vary between different kinds of hand tools. The prediction model is not only influenced by the type of hand tool, by the properties of the hand tool too.

\section{Conclusion}

The results of the study may have a contribution to the discussion of the difference between comfort and discomfort. The result of the pre-study show that treating comfort and discomfort in using hand tool as two opposites on continues scale is totally wrong. A comfortable hammer should be designed in a way so that the user does not face any difficulty while using the hammer and the user can perform the task with low hand grip force supply. Mitigating the adverse body effects such as pain in hand or fingers is also important in providing overall comfort.

The results of this study can be of help to understand which factors play important role in expected comfort and overall comfort after short time use and it could help the designers in designing of a comfortable hammer.

\section{Acknowledgement}

The authors acknowledge and duly appreciate all the professional workers and unprofessional users who, despite of their busy schedule helped us in our work and made this research task possible.

\section{References}

[1] M. Haapalainen, J. Kivistö- Rahnasto, and M. Mattila, "Ergonomic design of non- powered hand tools: An application of quality function deployment (QFD)," Occupational Ergonomics, vol. 2-3, pp. 179-189, 2000.

[2] P. Vink \& S. Hallbeck, "Editorial: Comfort and discomfort studies demonstrate the need for a new model," Applied ergonomics, vol. 43, no. 2, pp. 271-276, 2012.

[3] H. H. Hamberg-van Reenen, A. J. Van der Beek, B. M. Blatter, M. P. Van der Grinten, W. Van Mechelen, and P. M. Bongers, "Does musculoskeletal discomfort at work predict future musculoskeletal pain?" Ergonomics, vol. 51, pp. 637 $-648,2008$.

[4] P. G. Dempsey, R. W. McGorry, T. B. Leamon, and N. V. O"Brien, "Bending the tool and the effect on human performance: Further investigation of a simulated wire twisting task," AIHA Journal, vol. 63, no. 7, pp. 586-593, 2002.

[5] P. Vink, C. J. Overbeeke, and P. M. A. Desmet. Comfort experience. In: Comfort and design; principles and good practice, P. Vink Ed. Boca Raton: CRC Press, pp. 1-12, 2005.

[6] L. F. M. Kuijt -Evers, P. Vink, \& M. P. De Looze, "Comfort predictors for different kinds of hand tools: Differences and similarities," International journal of industrial ergonomics, vol. 37, no. 1, pp. 73-84, 2007.

[7] F. Freund, E. P. Takala, and R. Toivonen, "Effects of two ergonomic aids on the usability of an in-line screwdriver," Appl. Ergon., vol. 31, pp. 371-376, 2000. 
[8] S. R. Chang, S. Park, and A. Freivalds, "Ergonomic evaluation of the effects of handle types on garden tools," Int. J. Ind. Ergon., vol. 24, pp. 99-105, 1999.

[9] D. J. Habes and K. A. Grant, "An electromyographic study of maximum torques and upper extremity muscle activity in simulated screwdriving tasks," International journal of industrial ergonomics, vol. 20, pp. 339 -346, 1997.

[10] A. Chao, A. J. Kumar, C. T. Emery, N. D. Nagarajarao, and H. You, "An ergonomic evaluation of cleco pliers," in Proceedings of the IEA 2000/HFES 2000 Congress, pp. 4 -441-4-442, 2000.

[11] S. M. Eikhout, R. D. Bronkhorst, and M. P. van der Grinten, "Evaluation of a new scraper," in Proceedings of the 45th HFES Congress 2000, Minneapolis, 2001.

[12] L. F. M. Kuijt -Evers, L. Groenesteijn, M. P. De Looze, \& P. Vink, "Identifying factors of comfort in using hand tools," Applied Ergonomics, vol. 35, no. 5, pp. 453-458, 2004.

[13] L. Zhang, M. G. Helander, \& C. G. Drury, "Identifying factors of comfort and discomfort in sitting," Human Factors: The Journal of the Human Factors and Ergonomics Society, vol. 38, no. 3, pp. 377-389, 1996.

[14] R. W. McGorry, "A system for the measurement of grip forces and applied moments during hand tool use," Applied ergonomics, vol. 32, no. 3, pp. 271-279, 2001.

[15] G. L. Fellows and A. Freivalds, "Ergonomics evaluation of a foam rubber grip for tool handles," Applied Ergonomics, vol. 22, no. 4, pp. 225-23, 1991.

[16] E. Dumur, Y. Barnard, \& G. Boy, "Designing for comfort. Human factors in design,” pp. 111-127, 2004.

[17] D. S. Bisht \& M. R. Khan, "Ergonomic Assessment Methods for the Evaluation of Hand Held Industrial Products: A Review," 2013. 